This paper is part of the Proceedings of the $3^{\text {rd }}$ International Conference on Design,

\title{
Small-scale modelling of urban structure types for the cost evaluation in sanitary environmental engineering
}

\author{
M. Schulwitz ${ }^{1} \&$ T. Hillenbrand ${ }^{2}$ \\ ${ }^{I}$ ILS - Research Institute for Regional and Urban Development, Germany \\ ${ }^{2} I S I$ - Fraunhofer Institute for Systems and Innovation Research, \\ Germany
}

\begin{abstract}
Planners of urban infrastructures are confronted with a dilemma: uncertainty about the concrete effects of global megatrends on the relevant small scale hinders longterm planning while build infrastructures are mostly inflexible to short- and midterm changes. The presented approach uses 14 representative urban structure types for modelling the small-scale development of the population and the costs of water infrastructures in a dynamic scenario model. The results reflect the heterogeneous characteristics of different urban structures under changing conditions and thus can be a basis for more specific action recommendations. Furthermore, they illustrate the need for an integrated planning of urban development and water infrastructures to make use of simultaneous action windows and synergetic effects. Keywords: water infrastructure, infrastructure costs, costs modelling, small-scale modelling, scenario model, urban structure types, urban planning, demographic change.
\end{abstract}

\section{Introduction}

As Scholten et al. [1] stated, the main issue planners have to face during the planning process of urban water infrastructures is uncertainty. While the general effects of global megatrends like climate change or demographic change onto cities are broadly explored by research, their concrete small-scale impacts often remain uncertain. However, the small-scale level is most important for the planning of water infrastructures, as the physical connection between the consumer and the infrastructure supply takes place on this very local level (cf. [2]). 
Regarding demographic change, the past decades have shown that the intraurban development of population in German cities has been very heterogeneous, even if a city in general is constantly growing or shrinking. This is, because highly dynamic factors like the image, gentrification processes or a changing qualitative housing demand strongly influence the population development of a neighbourhood. Such factors are hardly predictable in a long-term planners' perspective and are impossible to implement on the municipal level, where most of the existing population forecastings are settled. In fact, shrinking neighbourhoods often are directly adjacent to growing neighbourhoods (cf. [3]).

This leads to the ambivalence of unoccupied housing supplies and underutilisation of existing infrastructures on the one hand and the expansion of settlement areas with new infrastructures being built on the other hand, resulting in a rising expenditure on local public infrastructure per capita in average.

In their fifth Assessment Report, the IPPC [4] discussed the various impacts of climate change on urban areas. While there is a common knowledge about the general challenges urban agglomerations will have to face, like rising temperature and sea levels in line with more frequent and intense extreme weather events, the authors pointed out that there are still "limits to understanding and predicting impacts of climate change at a fine-grained geographic and sectoral scale" $[4$, p. 550]. The precise prediction of urban heat islands or urban flooding areas is subject to a variety of highly dynamic systemic and cascading climate risks. Especially "[...] water supply and waste water management must confront these new climatic patterns and major uncertainties in availabilities and learn to respond to dynamic and evolving sets of constraints" [4, p. 557].

Demographic and climate change are two examples of framing conditions influencing the future preconditions for urban infrastructures. The uncertainty of the concrete small-scale effects is a challenging issue in the planning processes of piped infrastructures as they lack of flexibility to short-term changes. This is, because the costs of water infrastructure are dominated by long-term fixed costs, called sunk costs, due to the high investment costs, which strain the budget for 50 years and more. The German Association for Water, Wastewater and Waste [5] calculates a two-third share of fixed costs in the cost-structure of sewage systems, consisting of amortisation costs, interest rates and labour costs. And even the onethird share of flexible costs shows a remanent behaviour as they cannot be reduced to the same degree as the sewage amount decreases because of rising maintenance costs for under-worked pipes.

Apart from their cost-structure, water and wastewater infrastructures can be described as inflexible to short- and mid-term changes of their framing conditions due to technical-operational path-dependencies. Being built as a network, the piped elements of water infrastructure are part of a complex system and often provide carriage functions for affiliated parts of the system. Thus, a possibly required removal of elements of the system always has to consider the function of the concerned element for the system as a whole. Furthermore, the punctual elements of the system, like clarification plants, require minimum input amounts to ensure a reliable operation of the facility. Therefore, existing water 
infrastructures are not able to adapt to massive changes concerning their framing conditions in short term without investment measures.

The approach presented in this paper is based on the urban structural units method, which is well-established in spatial research (see e.g. [2, 3, 6, 7]). This method is used to calculate the small-scale development of the population and of the water infrastructure for different urban structure types (UST) in a scenariomodel. As the underlying research project included a case study for the German cities of Lünen, Altena and Porta Westfalica, the literature values for the key parameters were reviewed and supplemented due to an analysis of actual data from these cities. The specified small-scale results lead to more transparency concerning the long-term consequential costs of urban development and support the decision making in an integrated planning of urban and infrastructural development.

\section{The urban structure type approach}

In spatial research, clustering urban structures into different units or typologies is common to analyse urban development on different scales and concerning its multi-sectoral impacts. Especially in inter- or transdisciplinary research, this method can be used as an interface for an integrated analysis of urban, demographic and infrastructure development (cf. [2, 3, 6-8]).

\subsection{Urban structure types in spatial research}

Key characteristic of the structure type approach is the clustering of the heterogeneous urban building structures into preferably homogeneous UST. These UST feature a description of typical properties concerning the corpus and positioning of the buildings as well as a varying number of parameters referring to the particular research question. For example, Siedentop et al. have defined eight structure types for residential areas to analyse the follow-up costs of urban development [2, p. 42ff.]. In their approach, they derived the costs from the exemplary infrastructures of streets, water infrastructures, long-distance heating and social infrastructures. Other studies used UST to analyse the influence of different urban structures on the population development and the housing market, the different impacts on the environment, or the potential of urban open spaces for urban development (cf. [2, 8-10]).

Comparing the studies for German cities, lots of similarities between the identified UST can be found. Though the denominations differ, central characteristics concerning morphology and positioning of the buildings are remarkably consistent between the different structure types (cf. [2, 7-10]). As methodology and research focus varies between the studies, the homogeneity of the key characteristics can be understood as empirical evidence for the existence of typical UST in German cities.

Most of the UST identified in literature refer to urban structures for residential use (cf. $[2,6,8,9]$ ) as their focus is on modelling the population development and the resulting challenges for different sectors (e.g. housing market, urban 
infrastructure, use of public spaces). Studies more focussed on the constructional characteristics of different structure types, like the one done by Arlt et al., also include commercial and industrial areas in their clustering [10].

\subsection{Definition of 14 urban structure types}

As the underlying case study was focussed on the empirical analysis in three German cities, the used UST also had to reflect typical building structures of German cities. While there is a remarkable number of studies on building structure types in international research, distinct differences between the identified structure types can be stated, especially regarding different continents or cultural groups. Thus, the concentration on structure types of central European cities that can be found in German literature was pragmatic in regard of the empirical analysis. The intention while analysing literature was to find a combination of UST which were approved by different studies, represent a variety of typical building structures and imply key parameters for the modelling of the cost development in sanitary environmental engineering. The authors were able to identify 14 UST representing residential as well as commercial areas (see Table 1).

The 14 identified UST can be separated into eight UST which primarily serve residential needs (R.1-R.8) and five UST for commercial use (C.1-C.5). Intraurban mixed-use areas combine both usage types and could be assigned to both categories, but in regard to the modelling of the population development this UST was assigned to the residential usage types.

For each UST specified parameters were derived from literature (cf. [2, 6, 8, 9]) and proven by empirical analysis of real data from the three case study examples. These parameters can be divided into three categories:

- Descriptive parameters help to get an image of the morphology of the UST and to confine them using GIS software - meters of street per ha, number of storeys (for residential areas)/size of parcels (commercial areas), degree of sealing.

- Demographic parameters are used for the small-scale distribution of population and within the demographic model to calculate the future demographic development - population density, number of household members, age distribution.

- Infrastructure parameters are needed for the extrapolation of the average infrastructure amount - flat density, drain density (potable water), drain density (waste water).

One example of the parameters for each category is shown in Table 1. By using these parameters within a scenario model, the small-scale development of the population and the costs of sanitary environmental engineering can be calculated for the different UST on different spatial scales, also giving the possibility to combine different UST. 
Table 1: Urban structure types.

\begin{tabular}{|c|c|c|c|c|}
\hline UST (Code) & Scheme & $\begin{array}{c}\text { Degree of } \\
\text { sealing (\%) }\end{array}$ & $\begin{array}{l}\text { Sewage drain } \\
(\mathbf{m} / \mathbf{h a})\end{array}$ & $\begin{array}{l}\text { Population/ } \\
\text { ha }\end{array}$ \\
\hline $\begin{array}{l}\text { Traditional perimeter block } \\
\text { development (R.1) }\end{array}$ & & $70-80$ & $109-138$ & $204-254$ \\
\hline Line construction (R.2) & & $45-55$ & $250-400$ & $174-290$ \\
\hline $\begin{array}{l}\text { Apartment buildings in open } \\
\text { design/prefabricated slab- } \\
\text { buildings (R.3) }\end{array}$ & & $45-55$ & $87-119$ & $225-309$ \\
\hline $\begin{array}{l}\text { Past-1990 apartment buildings } \\
\text { (R.4) }\end{array}$ & & $45-55$ & 160 & $120-168$ \\
\hline $\begin{array}{l}\text { Dense single-family houses/ } \\
\text { terraced houses (R.5) }\end{array}$ & & $45-55$ & $123-130$ & $60-81$ \\
\hline $\begin{array}{l}\text { Detached single-family houses } \\
\text { (R.6) }\end{array}$ & & $30-40$ & $93-103$ & $30-41$ \\
\hline Village centre (R.7) & & $45-55$ & $62-86$ & $30-41$ \\
\hline Dispersed settlement (R.8) & & 20 & 83 & $21-41$ \\
\hline $\begin{array}{l}\text { Intra-urban mixed-use block } \\
\text { developments (R.9) }\end{array}$ & & $70-90$ & $109-138$ & $204-254$ \\
\hline UST (Code) & Scheme & $\begin{array}{c}\text { Degree of } \\
\text { sealing }(\%)\end{array}$ & $\begin{array}{l}\text { Sewage drain } \\
\text { (m/ha) }\end{array}$ & $\begin{array}{c}\text { Ø Size of } \\
\text { parcels (ha) }\end{array}$ \\
\hline Industrial Area (C.1) & & $75-90$ & $51-59$ & 2.7 \\
\hline Logistics park (C.2) & & $70-80$ & $51-59$ & 2.4 \\
\hline $\begin{array}{l}\text { Conventional commercial area } \\
\text { (C.3) }\end{array}$ & & $75-85$ & $68-78$ & 1.9 \\
\hline $\begin{array}{l}\text { Small-scale fragmented } \\
\text { commercial area (C.4) }\end{array}$ & & $65-75$ & $92-105$ & 0.6 \\
\hline $\begin{array}{l}\text { Technology and science park } \\
\text { (C.5) }\end{array}$ & & $65-75$ & 95-109 & 1.1 \\
\hline
\end{tabular}

Source: own illustration; data base: $[2,3,8,9]$ and own survey. 


\section{Modelling of urban structure types}

\subsection{Basic structure}

This model was developed to analyse the cost developments in water infrastructure systems at the level of small-scale UST. First, the model results are used to illustrate the cost structures and differences between various UST. Second, they also show long-term perspectives illustrating the influence of the expected changes as described above. The effects of important changes in the framework conditions are spatially differentiated and implemented in the model beginning with the municipal level through the district level down to the level of small-scale urban structures. The input data needed for the calculations are taken from the submodels. Based on the UST level, the costs of the infrastructure elements of urban water supply and wastewater disposal are documented. This three-level structure does not only ensure greater transparency of the impacts of the different developments; ultimately, the cost effects can also be aggregated in different configurations of spatial scales.

\subsection{Input data}

In principle, infrastructures can be subdivided into different levels of site development. The drinking water and wastewater infrastructure was distinguished as shown below for the subsequent calculations:

a) Internal infrastructure: this level covers the house connection sewers and the network of pipes within a neighbourhood or residential area.

b) Gross infrastructure: the gross infrastructure contains the connections and pipes linking functional units to higher level structures (main pipelines).

c) External infrastructure: the external infrastructure basically covers major components like waterworks or sewage treatment plants and their associated feeder and transportation pipelines.

The quantity structures of the water infrastructure, based on the UST parameters (e.g. specific lengths of pipelines and population density), were used as input data for the model. Costs were calculated based on specific cost data derived from published data on the cost situation in Germany (especially $[2,11$, 12]) and own evaluations. The information is separated into capital costs (annually occurring annuities) and operating costs which include maintenance costs (in $€ / \mathrm{m}$ of pipeline).

In the model, it is assumed that re-investment takes place once the life expectancy of 60 years has expired. The objective is to maintain the existing infrastructure system, that is, the capital costs that have to be taken into account remain the same while the operating costs are adjusted according to age and quality.

Based on these cost data, it is emphasised that the costs of the water infrastructure are mainly fixed costs, that is, they incur independently of the actual quantity of drinking water/wastewater or the actual number of residents to be supplied at the respective point in time. Further changes of framing conditions 
during the modelled period result from changes of the settlement area: Additional areas have to be considered in the costs of wastewater disposal due to the infrastructure associated with additional sealed surface areas. Furthermore, the possible additional costs for operation caused by a very strong under-utilisation of the piped networks have to be considered. Following Siedentop et al. [2], increased operating costs for sewers are calculated if utilisation drops below $50 \%$ (operating costs increase by $50 \%$ ), respectively below $15 \%$ (operating costs increase by $100 \%$ ).

\subsection{Population development}

Demographic changes can trigger growth and shrinkage processes at regional level, some of them directly adjacent to each other. Similarly, for the municipal level this means that developments at the level of neighbourhoods can also vary widely (cf. [3, p. 118ff]).

The forecasting of the small-scale demographic development is executed by a dynamic three-level population model. Step by step, the population structure is disaggregated down to the small-scale UST-level, starting from the highest level, which is the municipality. For the chosen municipality, a cohort-component model (cf. [14]) is carried out to forecast the demographic development till the year 2100, based on the age distribution of 2011 (census data) and the four components of population development (fertility, mortality, immigration, emigration. In this approach, several exemplary scenarios were predefined, while it is also possible to define and calculate own scenarios for the future development of the four components. The status-quo scenario used to calculate the results in section 5, presumes that all components remain steady at the level of the 2010-2012 average rates.

The first level of disaggregation is the district-level. The trend of population development and the relative age distribution of the municipal level are transferred onto the input number of inhabitants for the concerned district. Users of the demographic model can easily influence the district development by manually entering factors to adjust the age distribution and development trend of the district. This level allows local stakeholders to integrate their professional knowledge in the forecasting (e.g. divergent age distribution or assumed effects of already scheduled development measures) for a more precise projection of the population development.

The third level of the population model covers the spatial scale of a neighbourhood. Analysing data from the three case studies, specific parameters concerning the population development (e.g. variation on the age distribution, sensitivity concerning the municipal development trend) could be derived for the different kinds of neighbourhoods, which are classified as UST. In combination with the values from literature (see section 3.2), the UST serve as projection area for the intra-municipal population distribution and for a more precise forecasting of the small-scale population development. It is also possible to carry out an aggregated modelling for several UST, so that the calculation is done for a whole district in one step, while still acknowledging the specified characteristics of each UST within this district. 
Additionally, a simplified scenario model to calculate the future development of the settlement and transportation area till the year 2100 is attached to the population model. This model includes four scenarios for each of the three case studies, based on the extrapolation of the development of the settlement and transportation areas per capita between 2000 and 2012. Each of the scenarios uses different target values for the extrapolation, regarding the underlying assumptions (e.g. status-quo development, political objectives or recovery of settled areas).

\section{Results}

The developed cost model allows for differentiated analyses of the costs of water infrastructure and the future development of these costs in different structure types. The main analyses that can be done using this modelling approach are:

a) Comparative statements about the cost structures between different urban districts or different UST;

b) analyses of long-term developments; and

c) studies about the influence of different framework conditions such as demographic change or an increase of settlement areas.

The results for a) show huge cost disparities for the different UST. The disparities concerning the annual costs per capita range up to $400 \%$ for the showcased neighbourhoods in the Luenen case study (see Figure 1). In general terms, UST with a higher population density are more efficient. In other words, the UST R.2 or R.3 feature lower specific costs than, for example, the UST R.8, R.6 or R.5.

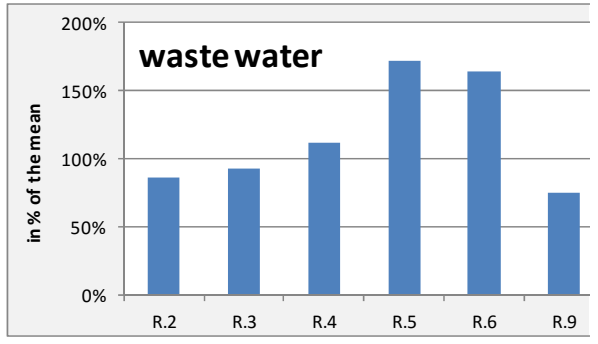

(a)

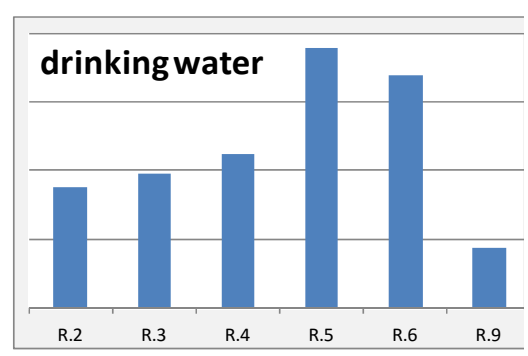

(b)

Figure 1: Comparison of the resident-specific infrastructure costs of wastewater (a) and drinking water (b) for a selected case-study neighbourhood (Luenen) in 2015.

Analyses of b) show that the modelled total costs of water infrastructure basically do not alter much in the long term if framework conditions remain constant. This only applies, however, if the potential changes that are currently being discussed and that are associated with additional costs, are not included in the cost calculations of wastewater treatment. These are, for example, changes due to more extensive legal requirements concerning the elimination of pollutants or resource efficiency. 
However, this picture changes dramatically if, in line with c), major changes of important framework conditions are taken into account and the specific costs per capita are considered (see Figure 2). Because the costs of water infrastructure are fixed costs to a large extent, overall costs do not change significantly with a decreasing (or even increasing) number of users, as long as no major conceptual adjustments are made. This means that the development of the specific costs is largely determined by changes in the number of users. For the reference scenario there is a considerable decline in the number of residents: approximately $-40 \%$ in Luenen and Porta Westfalica and approximately -70\% in Altena till 2065.

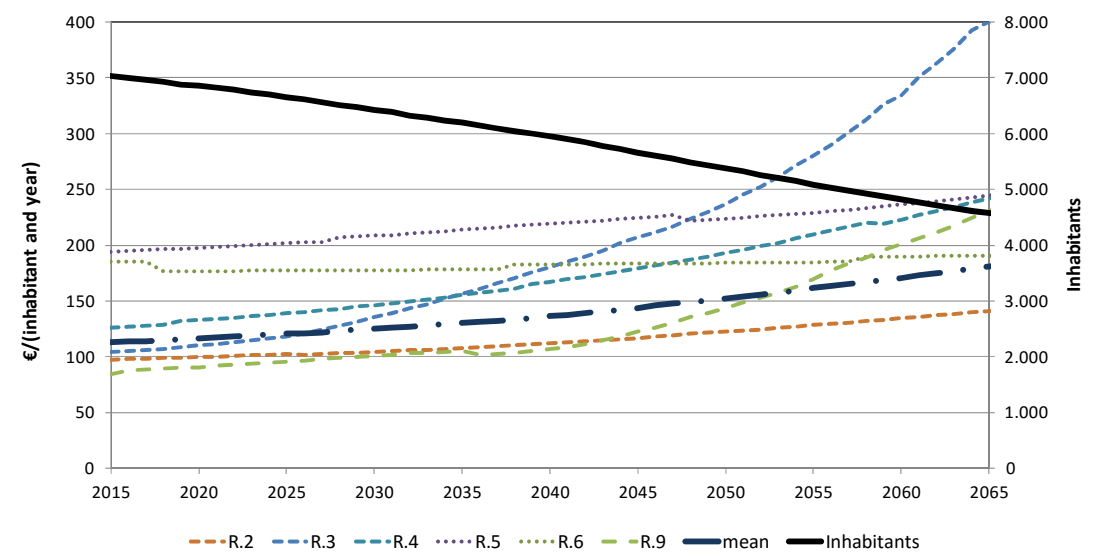

Figure 2: Development of the resident-specific wastewater infrastructure costs and inhabitants from 2015 to 2065 (Luenen).

The modelling approach allows for a differentiation at the level of the UST, which are strongly affected in varying ways by such demographic changes. For example, due to the population decline in the reference scenario, the specific cost figures increase by about $60 \%$ on the average for the three example districts within the period under observation of 50 years and by about $140 \%$ in Altena. For the most intensely affected UST, however, costs may be ten times higher as the average (see Figure 1). At the same time, however, partially substantial increases of the specific costs have to be expected, even in more densely populated UST, like R.3.

The different scenarios for the development of land use have a much lower impact on water infrastructure costs than the demographic development: differences of about 10 to 20 percentage points result for the different land use scenarios.

\section{Action recommendations and conclusion}

The results illustrate the need for strategic actions in urban districts and UST that feature or will possibly feature very high specific costs due to the expected developments. The following starting points for action can be distinguished: 


\subsection{Options spanning UST}

a) Integrated settlement-concepts to reduce land consumption: avoiding further dispersed expansion of settlement and transportation area including the associated expansion of the water infrastructure networks.

b) By adapting the tariff structure, usage-based fees could be charged and incentives could be created for more cost-efficient water infrastructure systems. The legal framework in Germany gives a relatively large scope to the operators of water infrastructure to change and optimize existing tariff structures (which, at the moment, in Germany, are characterized by a comparatively low consumption-independent standing charge component and a high usage-dependent share). Because of the high share of fixed costs, it might be worth considering introducing or increasing the share of the standing charge, basic fee or system price. This must only be allowed to cover the share of consumption-independent fixed costs. The benchmarks for this could be geared towards cost drivers such as topography, density of settlement/housing structure, length of pipelines or size of the connected properties.

c) Climate adaptation measures are needed in all UST, especially to deal with increased heavy rainfalls. It is becoming harder to sustain advanced flood protection based solely on drainage technology. Instead, holistic risk management that integrates all the local stakeholders and that propagates the adapted, water-sensitive design of town planning, urban development and architecture, is regarded as essential (cf. $[15,16])$.

\subsection{UST-specific options}

a) In low-density regions, the options include decentralised or semidecentralised wastewater concepts. Examples of innovative approaches are new designs for the centrally organised operation of small sewage treatment plants (combined with remote monitoring systems, cf. [18]), or more resource-based concepts such as DEUS21, Lübeck-Flintenbreite, Hamburg Water $\mathrm{Cycle}^{\circledR}$. These operate adequate treatment options with resource recovery by exploiting the collection of partial flows that, among others, consider the water-energy-context.

b) In low-density regions with long drinking water pipelines, demographic changes can, possibly intensified by climate changes, result in much higher specific costs and operational problems. Solutions are to decouple different supply tasks (provision of drinking water and water for fire-fighting), to avoid stagnation zones in the drinking water network by reducing (in the medium to long term) the pipes' diameter and to segregate drinking water networks in the sense of "self-purifying networks".

c) For higher density regions, integrated concepts of (waste) water management are possible options to improve resource and energy efficiency. Innovative concepts aim to recover the most important resources - collected by residential water management - water, nutrients and energy - in line with the principles of a closed loop economy (see review in [19]). Concepts have now also been developed that can be implemented in the stock of systems via 
relevant transitional phases (www.twistplusplus.de). The exact design of such integrated concepts has to be adapted to the UST-specific conditions.

The described novel approaches to further develop water infrastructure systems are usually complex technical systems at the intersection of the public and private sector, partially coupled with other fields of infrastructure (waste disposal, energy supply) and linked with impacts for both, the actual users and for other groups of stakeholders like operators, municipalities or local authorities (cf. [17]). It therefore makes sense to implement a comprehensive process that integrates all the relevant stakeholders.

Apart from being a more specific basis for the long-term planning of technical measures for a more efficient and sustainable sanitary environmental engineering, the results (see section 4) have shown that the heterogeneous building structure strongly influences the costs for the supply of each inhabitant. As the costs per capita show high disparities between the different UST, which will even grow in the future, the quantity and kind of urban development may highly influence the future costs of sanitary environmental engineering. Therefore, an integration of urban planning and (water) infrastructure planning is essential to avoid underutilisation of existing infrastructures and exponentially rising water fees. Identifying and synchronising bi- or even multilateral action windows will help to make use of synergy effects, increase the long-term efficiency of investment measures and be the basis to find the right period of time for possible, far-reaching system changes.

The results point out that a long-term strategy is essential in order to counteract in good time the possible increases in specific costs that result from the low degree of flexibility offered by conventional water infrastructure systems and their comparatively dynamic environment and changing framework conditions. The following steps are necessary to achieve this:

- Making a detailed inventory of the current situation and, based on this, analyses of future developments: The described modelling tools offer the chance to analyse long-term trends (population, land, specific costs) disaggregated to the level of districts and UST.

- Process to get all the relevant stakeholders involved (cf. [17]).

- Evaluating the options for action: given the overriding objective of "watersensitive" housing or urban development.

- Deriving a long-term strategy and concrete recommendations for action.

Adaptation measures should be taken as early as possible. The options described above can make a major contribution to achieving the objective of a sustainable further development of water infrastructure systems and ensuring their functionality and financeability in the long term, as well as avoiding making bad investments. 


\section{References}

[1] Scholten, L., Schuwirth, N., Reichert, P., Lienert, J. Tackling uncertainty in multi-criteria decision analysis - An application to water supply infrastructure planning. European Journal of Operational Research, 242(1), pp. 243-260, 2015.

[2] Siedentop, S., Schiller, G., Koziol, M., Walther, J., Gutsche, J.-M. Siedlungsentwicklung und Infrastrukturfolgekosten - Bilanzierung und Strategieentwicklung, Final Report. Federal Office for Building and Regional Planning, Germany (ed.), Bonn, 2006.

[3] Dittrich-Wesbuer, A., Mayr, A., Schulwitz, M. Demografischer Wandel, Siedlungsentwicklung und Abwasserinfrastrukturen - eine integrierte Betrachtung lokaler und regionaler Entwicklungsperspektiven (Chapter 5). Die Governance der Wasserinfrastruktur. Band 1: Rahmenbedingungen, Herausforderungen und Optionen, ed. E. Gawel, Duncker \& Humblot: Berlin, pp. 117-138, 2015.

[4] Revi, A., Satterthwaite, D.E., Aragón-Durand, F., Corfee-Morlot, J., Kiunsi, R.B.R., Pelling, M., Roberts, D.C., Solecki, W. Urban Areas (Chapter 8). Climate Change 2014: Impacts, Adaption and Vulnerability. Part A: Global and Sectoral Aspects. Contribution of Working Group III to the Fifth Assessment Report of the Intergovernmental Panel on Climate Change, ed. C.B. Field, V.R. Barros, D.J. Dokken, K.J. Mach, M.D. Mastrandrea, T.E. Bilir, M. Chatterjee, K.L. Ebi, Y.O. Estrada, R.C. Genova, B. Girma, E.S. Kissel, A.N. Levy, S. MacCracken, P.R. Mastrandrea, L.L. White, Cambridge University Press: Cambridge, UK and New York, USA, pp. 535612, 2014.

[5] German Association for Water, Wastewater and Waste - DWA (ed.). Wirtschaftsdaten der Abwasserbeseitigung, Hennef (Sieg), 2011.

[6] Böhm, P. Urban Structural Units as Key Indicator for Monitoring and Optimising the Urban Environment (Chapter 88). Urban Ecology, ed. J. Breuste, H. Feldmann, O. Uhlmann, Springer-Verlag GmbH \& Co. KG: Berlin, pp. 442-445, 1998.

[7] Banzhaf, E., Höfer, R. Monitoring Urban Structure Types as Spatial Indicators with CIR Aerial Photographs for a More Effective Urban Environmental Management. IEEE Journal of Selected Topics in Applied Earth Observations and Remote Sensing, 1(2), pp. 129-138, 2008.

[8] Westphal, C. Dichte und Schrumpfung, Kriterien zur Bestimmung angemessener Dichten in Wohnquartieren schrumpfender Städte aus Sicht der stadttechnischen Infrastruktur, IÖR Schriften 2008(49), Leibniz-Institut für ökologische Raumentwicklung e.V.: Dresden, 2008.

[9] Blum, A., Gruhler, K. (eds). Typologien der gebauten Umwelt Modellierung und Analyse der Siedlungsentwicklung mit dem Strukturtypenansatz. Shaker Verlag: Aachen, 2010.

[10] Arlt, G., Hennersdorf, J., Lehmann, I. Städtebauliche Strukturtypen zur Bestimmung von Bodenversiegelung und Grünaustattung in den kreisfreien Städten Deutschlands und deren Stadtregionen (Chapter 3). Typologien der 
gebauten Umwelt, Modellierung und Analyse der Siedlungsentwicklung mit dem Strukturtypenansatz, ed. A. Blum, K. Gruhler, Shaker Verlag: Aachen, pp. 41-60, 2010.

[11] ATT, BDEW, DBVW, DVGW, DWA, VKU, Profile of the German Water Sector 2015. Bonn: Wirtschafts- und Verlagsgesellschaft Gas und Wasser http://de.dwa.de/tl_files/_media/content/PDFs/StOeP/WEB_brachenbild_ ENGL_wasserwirtschaft_2015_a4_25062015.pdf.

[12] Ecoplan (eds.), Wirtschafts- und Umweltstudien: Siedlungsentwicklung und Infrastrukturkosten. www.are.admin.ch/dokumentation/publikationen/ 00168/.

[13] DWA: Leitlinien zur Durchführung dynamischer Kostenvergleichsrechnungen (KVR-Leitlinien). Deutsche Vereinigung für Wasserwirtschaft, Abwasser und Abfall, Hennef, 2012.

[14] Preston, S.H., Heuveline, P., Guillot, M. Demography: Measuring and Modeling Population Processes, Blackwell: Oxford, 2000.

[15] DWA, Starkregen und urbane Sturzfluten - Praxisleitfaden zur Überflutungsvorsorge; DWA Themen 2013(1), 2013.

[16] EPA, Climate Ready Water Utilities - Adaptation Strategies Guide for Water Utilities. www.epa.gov/sites/production/files/2015-04/documents/ updated_adaptation_strategies_guide_for_water_utilities.pdf.

[17] Hiessl, H., Hillenbrand, T., Klug, S., Lange, M., Vöcklinghaus, S., Flores, C., Weilandt, M. Nachhaltige Weiterentwicklung kommunaler Water infrastructureen - Strategischer Planungsprozess unter Einbindung aller wesentlichen Akteure. energie | wasser-praxis, 2012(4), pp. 13-17, 2012.

[18] Niederste-Hollenberg, J., Hillenbrand, T., Ungermann, A., Lachenmayer, E. Zentraler Betrieb dezentraler Anlagen: $z^{*} \mathrm{dez}$ - ein innovatives Betriebsund Organisationsmodell für die dezentrale Abwasserentsorgung. Korrespondenz Abwasser, 2016.

[19] Tilley, E., Ulrich, L., Lüthi, C., Reymond, P., Zurbrügg, C. Compendium of Sanitation Systems and Technologies, 2nd revised edition www.eawag.ch/ fileadmin/Domain1/Abteilungen/sandec/schwerpunkte/sesp/CLUES/ Compendium_2nd_pdfs/Compendium_2nd_Ed_Highres_1p.pdf. 